\title{
End-user centred Adaptation Process of an Educational Exergame to Mobile Platforms
}

\author{
Bernardo Benites de Cequeira - Universidade Feevale - bcerqueira@feevale.br \\ Débora Nice Ferrari Barbosa - Universidade Feevale - deboranice@feevale.br \\ João Batista Mossmann - Universidade Feevale - mossmann@gmail.com
}

\begin{abstract}
This work presents the educational Exergame "The Incredible Adventures of Apollo \& Rosetta in Space" adaptation process to mobile platforms, specifically Tablets. The Exergame was developed for Elementary School children in the school context, presented in previous work. The objective of this work is to propose a combination of three distinct end-user centered techniques in the process of the game adaptation: 1) evolutionary model of software development aimed for games; 2) non-participant observation on game applications with voluntary participants; 3) semi-structured interview with the participants. The methodology allowed the project's development team to constantly evaluate the game adaptation through prototypes and user tests with four voluntary participants. These user tests were done in pairs during three sessions, with 1hour session per week. As the results indicated, this end-user centered development enabled an effective portability process of the game between platforms.
\end{abstract}

Keywords: exergame; mobile game; game adaptation; executive functions; inhibitory control.

Resumo: Este trabalho apresenta o processo de adaptação do Exergame educacional "As Incríveis Aventuras de Apollo \& Rosetta no Espaço" para plataformas móveis, como tablets. O jogo foi desenvolvido para uso no contexto educacional em crianças do Ensino Fundamental I, apresentado em trabalhos anteriores. O objetivo deste trabalho é propor uma combinação de três técnicas distintas centradas no usuário para o processo de adaptação do jogo: 1) modelo evolucionário de desenvolvimento de software voltado para jogos; 2) observação não participante de aplicações com voluntários; 3) entrevista semiestruturada com os sujeitos. A metodologia possibilitou uma constante avaliação da adaptação entre plataformas pela equipe de desenvolvimento, bem como testes com quatro sujeitos voluntários. Os testes com usuários foram realizados em pares em 3 sessões, uma por semana com 1 hora de duração cada. Os resultados indicaram que este desenvolvimento centrado no usuário final possibilitou um processo de portabilidade efetivo do jogo entre as plataformas.

Palavras-chave: jogos ativos; jogos móveis; adaptação de jogos; funções executivas; controle inibitório.

\section{Introduction}

Exergames are defined as a game genre which utilizes the body movement for the game inputs instead of a joystick. The body movements of the player are interpreted as data input by a movement sensor device which translates and associate them to specific meanings and commands inside the game, thus transforming three-dimensional movement in physical space into computational system inputs (Finco et al., 2015). This technology associated to physical exercise shows relevant results for its ability to stimulate the body aligned with executive components stimuli (Finco et al., 2015).

Currently, there are many studies in the neuropsychology field related to the executive functions (EF) (Diamond, 2013; Friedman and Miyake, 2017), which are a set of cognitive skills and behavior regulations needed to handle the everyday tasks. V. $18 \mathrm{~N}^{\circ} 1$, julho, 2020 RENOTE DOI: 
Interventions aimed at exercising EF show that it is possible to exercise, stimulate and improve individual's abilities through certain cognitive stimulation programs (Diamond, 2013; Diamond and Lee, 2011; Diamond and Ling, 2016; Thorell et al., 2009).

Computerized programs designed for cognitive stimulation, such as digital games, have been studied in the EF intervention field in order to verify their potential for stimulation (Diamond and Ling, 2016; Thorell et al., 2009). Mossmann (2018) proposes an Exergame for cognitive stimulation, titled "The Incredible Adventures of Apollo \& Rosetta in Space" (Apollo \& Rosetta), which was developed aiming for the inhibitory control (IC) stimulation in Elementary School children (Mossmann et al., 2017). The game was built by a multidisciplinary team to address several aspects of the IC, with 7 different activities, each of which demands the player to behave, perform movements in a specific way, use their own body to interact and accomplish what is proposed in each activity. The cognitive stimulation events aim to stimulate the IC through visuospatial, visual and sound oriented activities.

The objective of this paper is to propose a combination of three end-user centered techniques, which were applied in the adaptation of the IC stimulation exergame into a mobile platform game. The adaptation process methodology included: 1) an evolutionary game development model; 2) game application with non-participant observation; 3) semi structured interview with the application's participants.

\section{Executive Functions}

Studies have shown possibilities in helping children to develop and even improve participant's EF through tasks which aim for exercising different cognitive aspects. These exercises include tasks to train reasoning, planning, memory, attention and inhibition, for example. Investigations also associate the EF to the daily behavior of children, where the correlations found includes questions such as school success and socio-affective functioning (Blair and Razza, 2007; Bull et al., 2008). Other studies confirm these findings and demonstrate that good development of the executive skills is required to ensure proper school development, professional career and many other daily aspects (Diamond, 2013; Hughes and Ensor, 2007; Jurado and Rosselli, 2007). It was also showed that the maturation of these skills occurs since early childhood (Bernier et al., 2010) on a long journey to the adulthood (Conklin et al., 2007). Therefore, exercising the EF can be also a strong stimulus towards success related to reading, writing and mathematics (Toll et al., 2011; Welsh et al., 2010), which raises the urge for the development of programs aimed for EF stimulation and its effects in individual's life, especially for children.

Diamond (2013) states that the EF consists in a family of three, interrelated core skills that are needed for the higher cognitive processes of the individuals, to accomplish their daily tasks:

1) Working Memory, responsible for managing, relating, connecting and handling current to previous information, which is essential for reasoning, problem solving and creative thought of individuals.

2) Inhibitory Control, responsible for braking and inhibiting impulses or behaviours, emotions and inappropriate or distractive thoughts, enabling self-control and non-habitual responses according to the demands of each situation faced by the individual.

3) Cognitive Flexibility, responsible for switching attentional focus between different tasks, to adapt to changing environments and be able to change perspectives.

The IC is a skill that acts on the individuals' behavioural aspects to control and restrict inappropriate actions or thoughts. This ability allows the individuals to choose between different responses and reactions to certain situations or objectives. Also, this cognitive 
aspect is responsible for the inhibition of a tendency or reaction, and therefore to think correctly before committing an action, providing the choice of different responses beyond the usual ones, or impulses (Diamond, 2013). Therefore, proper stimuli of this cognitive process, and also the EF group as a whole, could improve individuals' actions in front of different everyday situations, including those related to the school environment, especially when aimed for cognitive stimulation in children. However, it is still unclear whether computerized training or games can improve the IC or not (Diamond and Lee, 2011; Diamond and Ling, 2016).

A research study from Diamond and Ling (2016) also indicates contradictions in the research evidences regarding the effectiveness of computerized program approaches in EF training, especially for IC, thus demonstrating the necessity to further investigate in areas destined to EF stimulation. Controversies remains on the resulting stimulation of the participants (Buelow et al., 2015), the methodologies employed (Buschkuehl and Jaeggi, 2010; Au et al., 2015; Redick et al., 2015) and the reproduction of the results in other studies (Diamond and Ling, 2016) raising the need for discussions and further investigations in EF improvements for children.

\section{Exergame aimed for Inhibitory Control Stimulation}

A multidisciplinary team was assembled for the development and execution of the Apollo \& Rosetta Exergame project. This group encompassed professionals and experts from various fields such as game development, screenwriting, programming, voice actors, pedagogy, computer science, applied computing in education and neuropsychology.

Based on an original sci-fi ludic and aesthetic narrative for elementary school children, the story unfolds with two brothers who love observing the outer space. The program of cognitive stimulation is initiated from this narrative. The seven mentioned minigames challenges the player with different kinds of IC events, which must be accomplished to advance in the game levels. Also, each activity was designed for a continuous increase of executive difficulties, which are contextualized through the game's narrative, and therefore are suitable from less experienced to most advanced players. The exergame activities are explained in further descriptions.

In Activity 1 -Explorer, the player's character surfs in space towards the horizon. The objective of this activity is to collect multiple items that are blue marked on a screen list, or to avoid those that are marked red on the same list. The player guides laterally the character with the body, to reach items or to avoid obstacles. The list of allowed and redmarked items changes from level to level; hence this activity requires the inhibition of the action of collecting all the items automatically and demands that they focus on the list. Also, the activity demands the player to jump, crouch or to dodge the incoming obstacles.

In the Activity 2 - Deciphering Codes, the player's objective is to activate with hands or feet the four indicated letters on the screen. Each time, the game indicates a letter for the player. From time to time, a character in the game says a single word to the player. Therefore, every time the character says a word, the player must pay attention to the sound stimuli and compare whether the word's first letter matches the indicated letter on the panel or not. In case they match, the player must press a special button for this occasion in the screen, otherwise, they should keep the instruction. This activity stimulates attention and verbal comprehension, as the player's tendency to always perform with what is indicated is challenged for the player to succeed.

In Activity 3 - Particle Accelerator Tunnel, the purpose is to guide the character with lateral body movements through a tunnel, dodging obstacles which appear along the way. There are two alternating moments: In the first moment, the player's third person camera V. $18 \mathrm{~N}^{\mathrm{o}} 1$, julho, 2020 RENOTE DOI: 
aims for the horizon showing the back of the character and obstacles. From time to time the camera inverts during a short period, which consists in the second moment. During this special moment, the game commands are reversed, so that the player's movement to the left results in the character's moving to the right, reciprocally, thus breaking the movement pattern. Therefore, the player must maintain focus to keep up with the character's required movement in order to avoid the upcoming obstacles.

In Activity 4 - Jumping Asteroids the player's objective is to jump and step in the indicated colored zones in the screen, aware of a panel with four monitors which corresponds to four colored asteroids under the character's feet. Each round of this activity substitutes these asteroids and their colors, and the panel will indicate a new pair of colors, which the player must jump and step on the corresponding colored asteroids. Although, a list of "hot" colors on the left side of the screen demonstrates colors that shouldn't be stepped on. Thus, the activity demands the inhibition of the usual response by the player, as eventually it requires the opposite move to the usual rule of following what is indicated. So, the activity demands for quick and different responses from the player in each round, and requires him not to generalize their actions from level to level, as the list of "hot" colors change meanwhile.

In Activity 5 - Galactic Art the objective is to hit with the hand on colored balls that appear flying on the screen as space pipes toss them mid-air constantly, in order to paint a canvas on the scene. The player has to avoid black and white colored balls while painting the canvas. Eventually during the level, space flies invades the screen to distract the player, to make annoying noises and mess with the picture as the player score diminishes, and should be scared away as soon as possible. This activity inhibits the player's tendency to hit every ball seen in order to get a higher score. Also, manage to lose some colored balls to scare away the space flies, thus working with factors such as attention, inhibition and reward.

In Activity 6 - Stellar Laboratory the player's objective is to collect most numbered and colored "spatial vitamins" as possible, which randomly appears into four colored and numbered tubes in the screen. The players must reach with their hands or feet four buttons on the screen, which corresponds to the tubes, in order to correctly collect the spatial vitamins in a determined spot of the tube. Although, the vitamins should not be collected if their number or color does not match the tube in which they are in. Thus, the activity demands the inhibition of the tendency to collect all the vitamins automatically, keeping him constantly aware of every element in the scene.

In Activity 7 - Challenge of the Opposites, the player rides a space platform and must collect objects that appear to his left or right, using hands or feet according to what is voiced by a character present in the game named Tivo. The objective of the game is to collect the correctly indicated object, and inhibit the tendency to collect the opposing object. Eventually, Tivo's brother Ovit can substitute the character, indicating the wrong collectables momentarily, with opposite voice instructions, which must be performed contrary to what is indicated. Therefore, the activity demands the player's inhibitory control and verbal comprehension in order to always perform the correct choices.

\section{A method for the adaptation of the Exergame aimed for Inhibitory Control stimulation into mobile platforms}

In order to adapt a digital game between platforms, several questions must be taken in consideration and, besides transposition of the player's controls or inputs, the most important of all: the fun element (Koster, 2013). Kanode and Haddad (2009) proposes a discussion on the challenges related to software development (SD) processes with aims 
to an immersive experience, claiming that the SD process for games should focus on keeping the ludic and fun features for the game to be enjoyable. Therefore, a game adaptation between platforms should consider SD issues and user interaction (Kanode and Haddad, 2009), as well as aspects such as game balance, gameplay features, and design aimed for a fun experience (Koster, 2013).

The adaptation process of the game Apollo \& Rosetta was based on an evolutionary model for game development proposed by Baba and Tsang (2001). This model has an interactive development nature, with recurrent revisions in which prototypes are used as a mean to encompass programming tasks, user tests and evaluation, in order to influence new development decisions in a cyclic and spiral way. The technique is divided into a cycle of five stages. When the evaluation stage is analyzed by the development team, a new cycle unfolds, taking on questions and issues raised by the previous one. As an example, the first cycle of this end-user centric technique occurred as follows:

In the Inspiration stage, ideas, perspectives and objectives were discussed with the whole team, aiming for the directions and milestones of the project. Meetings were held with the part of the game's original development team and other researchers involved in the adaptation.

Next, in the Concept stage were created the visual representations, conceptual sketches and game modification's spreadsheets in order to summarize and define the goals of that development cycle, along the role and tasks for each team member to fulfil.

Following, in the Design stage, the team defined, organized and reviewed with other members all structural changes needed for that game adaptation cycle, such as programming, visuals, game design and instructions which needed modifications, for example.

In the Development stage, the team started the execution and prototyping of the planned, reviewed and agreed tasks. In this stage, the team worked thoroughly in tasks such as revision of 3D elements, creation and implementation of 3D animations, project migration to an updated game engine version and optimization for the application to run on tablets considering the platform's limitations.

Finally, in the last stage of the cycle, Evaluation/Testing, user tests occurred with the intended target group of the product (Elementary School children) with the game in the new platform. Two volunteers participated in the first evaluation. These participants have never had any contact with the game or project previously.

Every stage of the technique was designed according to the development team's ability to adapt the game in matters of time, human resources, infrastructure, and therefore does not represent a unique way use it, as it is a very flexible technique. These guidelines should be considered as the development of each project team or manager sees fit. In the case of the Evaluation stage, the user test was performed with two participants in three sessions during three weeks, once a week with approximately one hour of testing conducted by a research assistant. The game was installed in two Galaxy A Tablets, one for each subject. The children could interact freely with one another while playing the activities, as demonstrated in Figure 01. The user tests were recorded for further analysis of the participants interaction with the mobile platforms. Meanwhile, the research assistant took notes through non-participant observation on what was being evaluated from this cycle, such as the participant's interaction with the platform and the activities. The activities were played for 5 minutes each, and by the end of each testing, a quick semi structured interview was conducted with the participants, in order get their impressions related to the activities, before proceeding to the next one.

Next, the project development team watched the recording, discussed, categorized and analyzed the taken notes and interview during the application. Based in this gathered 
information, spreadsheets with necessary changes for the mobile game were organized and taken into consideration in the start of a new cycle of development of the end-user centered technique.

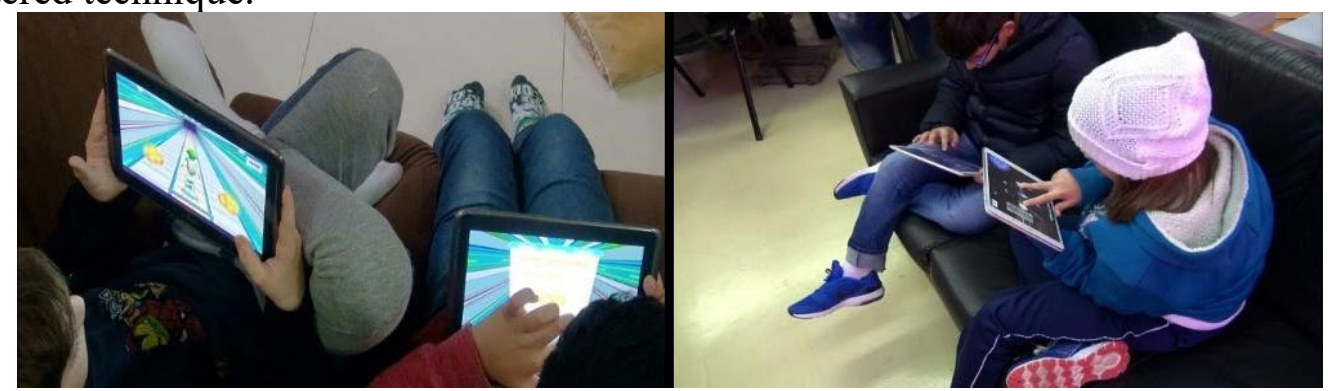

Figure 01 - Volunteer children participants in the user tests.

After the changes established were implemented in the first development cycle, a second user test was performed with two different children from the target audience. The same evaluation process was done to verify if the previous questions were properly solved, as well as new changes made in the game balance of the activities. Thus, with the results in each cycle, it was possible to identify and execute the necessary changes, demonstrating what resulted from the combination of techniques aimed at game development focusing on the needs raised by the users during the evolutionary development process.

\section{Results and Discussion}

The results of the methodology employed consisted in a large set of changes in the game. Table 1 summarizes the initial changes, discussed, raised and implemented by the development team prior to the tests. This phase enrolled members of the original development team of Apollo \& Rosetta together with the team responsible for the adaptation for mobile platforms. As the evolutionary model stages were developed according to the methodology, the data obtained, and the modifications generated by the first application with the subjects are demonstrated in Table 2. Furthermore, as the cycles restarted, Table 3 shows the last turn in the development cycle, raising the identified changes related to the second user test with the participants.

The initial modifications discussed by the development team regarding the adaptation were related to the inputs for each activity, since each one of them demanded different body movements from the players in the Exergame version. Also, the team raised issues related to what was necessary for the players to understand the game mechanics intuitively. Thus, changes were made in every horizontal and vertical command movements for the player in the correspondent activities, originally performed with their bodies. These commands were adapted initially to Swipe action (finger slide through the screen) on the mobile platform.

Activities in which the player had to reach objects, such as interactive panels or moving objects, the interaction with the device was added through touchscreen. Therefore, for the players to interact with the panel, they should press directly over the objects/buttons.

Moreover, changes were made to the animation of the game main characters. Since the player's body interaction with the Exergame used to automatically animate the characters, there was a necessity to develop motion animation for the them that corresponded to the player's interaction with the device and game environment. These changes occurred in in six out of seven activities, such as animation for the character to stand over a moving hoverboard, animations to raise the character's arm, for example.

V. $18 \mathrm{~N}^{\mathrm{o}} 1$, julho, 2020 RENOTE DOI: 
Along with these changes, modifications were made in the activities' tutorials and instructions regarding the game interactions, as well. Since the rules of the game interaction changed according to the new platform, new instructions did substitute the previous ones for better understandability of the demanded commands from the game. Table 1 shows the sum of the first set of changes of the game adaptation between platforms.

Table 1. General changes spreadsheet for basic game adaptations before the first user test;

\begin{tabular}{lll}
\hline & \multicolumn{1}{c}{ EXERGAME } & MOBILE GAME \\
\cline { 2 - 3 } & Jump & Swipe up \\
\cline { 2 - 3 } & Crouch & Swipe down \\
\cline { 2 - 3 } $\begin{array}{l}\text { Inputs: } \\
\text { Programming hands }\end{array}$ & Use feet & Buttons for interaction (hands) \\
\cline { 2 - 3 } & Body movement & Buttons for interaction (feet) \\
\cline { 2 - 3 } & Body interaction with object & Swipe left / right (sideswipe) \\
\cline { 2 - 3 } & $\begin{array}{l}\text { Character animation according to the } \\
\text { body movement captured }\end{array}$ & $\begin{array}{l}\text { Character animation according to buttons and object } \\
\text { interaction in game }\end{array}$ \\
\cline { 2 - 3 } & Body movement for pause & Pause button added on screen \\
\hline \multirow{3}{*}{$\begin{array}{l}\text { Tutorials: } \\
\text { Narrative }\end{array}$} & Fand placement instruction & Push the hand buttons instruction \\
\cline { 2 - 3 } & Feet placement instruction & Push the feet buttons instruction \\
\cline { 2 - 3 } & General movement instruction & Swipe commands instruction \\
\cline { 2 - 3 } & Body interaction with objects & Interact with object by touchscreen instructions \\
\hline \multirow{3}{*}{ Visual: Design } & Collect items with hands & Button for hands added \\
\cline { 2 - 3 } & Collect items with feet & Button for feet added \\
\cline { 2 - 3 } & Masks in the tutorials & Masks replacement \\
\cline { 2 - 3 } & Body movement animates the character & Added animations for character movement and interaction \\
\hline
\end{tabular}

After the initial changes were made for the game to run properly in mobile devices according to the team's schedule, the first user test was performed according to the evaluation stage of the cyclic development. The team's analysis from the non-participant observation and semi structured interview with the participants indicated that, firstly, the Swipe movements introduced did not fit the intended gameplay with the device. The analysis indicated that players would often get uncomfortable with activities that demanded higher number of swipe movement per level than others. This issue was observed when the players often changed the hand that held the device while the other hand had to perform the movement, as this would get their arms tired eventually.

Therefore, the Swipe command (lateral finger slide in the screen) was replaced by the lateral inclination of the device, through the accelerometer detection. Activities that needed vertical swipe (up/down finger slide in the screen) were replaced by buttons indicating to go up (jump) or descend (crouch).

The development team also noticed that some of the interactive elements on the game screen were arranged too close for the players to press in the right spot in the scene, consequently inducing them to miss their target due to the proximity of these elements. Hence, buttons were added in the interface in order to provide an appropriate interaction in activities that relied in interactive elements in their gameplay.

Finally, the participants of the first game evaluation tests complained that a faster rhythm was needed in some activities, such as the Particle Accelerator Tunnel. This was expected from the team, since the activities' rhythm in the original Exergame were not intended to exhaust the players. Besides, the movement detection technology had some limitations which should also be adjusted in the new platform. So, changes were made in the validation of user's interaction with the mobile platform, since the original game had a time window in order to wait for the players to raise their arms, legs, or even jump, and V. $18 \mathrm{~N}^{\mathrm{o}} 1$, julho, 2020 RENOTE DOI: 
to properly read these inputs. The validation was reduced to almost instantly, and the game rhythm received a faster difficulty incrementation in activities' levels.

The adaptations made to the mobile game are shown in Table 2, which compares them to the required changes made by the development team after the aforementioned analysis, according to the team's analysis and the participants feedback.

Table 2. General changes spreadsheet made after analysing the collected information from the first user test with the two volunteer children.

\begin{tabular}{|c|c|c|}
\hline & MOBILE GAME ON TEST & MOBILE GAME AFTER THE TEST \\
\hline \multirow{6}{*}{$\begin{array}{l}\text { Programming } \\
\text { (Inputs) }\end{array}$} & Swipe up to jump & Jump button added \\
\hline & Swipe down to crouch & Crouch button added \\
\hline & Swipe left / right for movement & Device inclination (Accelerometer) \\
\hline & Interaction with the objects on the scene & Interaction buttons added \\
\hline & Play validation (1 second) & Play validation - instantly \\
\hline & Slower activities & Faster activities' level difficulty increase \\
\hline \multirow{4}{*}{$\begin{array}{l}\text { Narrative } \\
\text { (Tutorials) }\end{array}$} & Swipe up instruction to jump & Instruction for pressing jump button \\
\hline & Swipe down instruction to crouch & Instruction for pressing crouch button \\
\hline & Sideswipe for lateral movement & Device inclination instruction \\
\hline & Interact with object by touchscreen & Interact with object by touching related buttons \\
\hline \multirow{4}{*}{ Design } & Disposition of interactive elements on screen & Buttons for interaction added on screen \\
\hline & Swipe up & Button design to jump \\
\hline & Swipe down & Button design to crouch \\
\hline & Sideswipe & Instruction for device inclination design \\
\hline
\end{tabular}

The non-participant observation and the session's footage indicated that the players were forced to play some activities with only one hand while the other had to hold the equipment, or to play the activities with the device above their knees or some surface to manage a successful play, as well as reaching the buttons arranged near the centre of the game interface. Thus, the team decided to make changes to the interaction by focusing on the game interface layout.

The new layout implemented enabled the players to maintain both hands to hold the device in most of the activities (six out of seven), minimizing the need for any surface support due to getting tired for playing the game on mobile platform. The changes made in the layout rearranged the buttons related to previously interactive (touchable) elements to be as close to the player's hands as possible. This change was made to prevent the players from contracting or stretching excessively their thumbs, and also to be able to reach them easily in the game's interface. At this stage of the development, new voice recordings for the narrative were made and implemented in the game for the new instructions. These changes were implemented in the game after the second evaluation with the participants, and are summarized in Table 3.

Table 3. Changes spreadsheet done after gathering all the information from the second user test with the other two volunteer children.

\begin{tabular}{lll}
\hline & MOBILE GAME ON TEST & MOBILE GAME AFTER THE TEST \\
\hline $\begin{array}{l}\text { Programming } \\
\text { (Inputs) }\end{array}$ & $\begin{array}{l}\text { Abrupt inclination not according to } \\
\text { accelerometer reading (Undetected) }\end{array}$ & Accelerometer adjustments \\
\hline $\begin{array}{l}\text { Narrative } \\
\text { (Tutorials) }\end{array}$ & Ambiguous tutorial instructions & Instructions revised and rewritten \\
\cline { 2 - 3 } Design & Textual instruction without sound or voices & $\begin{array}{l}\text { Recording and insertion of new speech lines in the } \\
\text { game }\end{array}$ \\
\hline & $\begin{array}{l}\text { Buttons disposed near the centre of the } \\
\text { screen }\end{array}$ & $\begin{array}{l}\text { Buttons redisposition for proximity to the screen } \\
\text { borders according to the user's hands. }\end{array}$ \\
\cline { 2 - 3 } & $\begin{array}{l}\text { Buttons disposed too close to the edges of } \\
\text { the screen }\end{array}$ & $\begin{array}{l}\text { Button redisposition for proximity to the user's fingers } \\
\text { holding the device }\end{array}$ \\
\hline
\end{tabular}

The Figure 02 shows an example of "Explorer" activity in Exergame format and the latest version of the mobile game with changes to the design layout, respectively. 

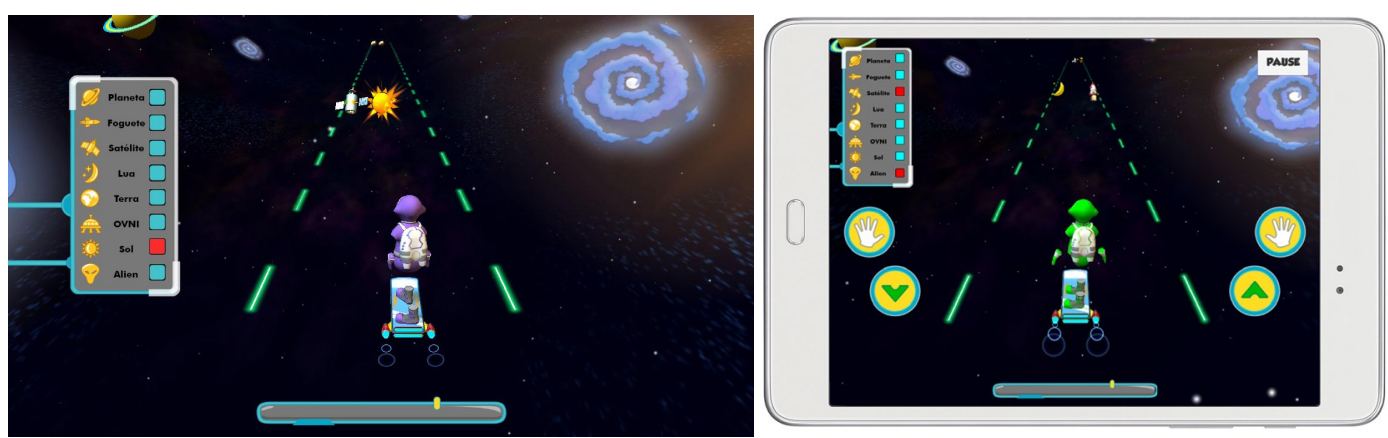

Figure 02 - Exergame and tablet version, demonstrating the new layout of the buttons for interaction and elements list. Buttons: "use hands" and crouch/jump buttons. The lateral movement of the character is done using device inclination.

\section{Final Considerations}

The objective of this paper was to propose a combination of end-user centered techniques in order to perform the adaptation of a cognitive stimulation Exergame into mobile devices, such as tablets. User tests were applied with voluntary participants according to the techniques proposed in the methodology - cyclic development model, semi structured interview and non-participant observation - in order to assess and evaluate the changes made by the development team during the process, gathering important feedback directly from the end-users. Considering that the cyclic adaptation process enables the continuous improvement of the game until the product is considered ready to be used, the development team aimed for a future use in a school intervention with the game in mobile platforms.

Finally, the collected data with the participants through the proposed methodology in this work demonstrated reliable information to understand the needs of the game adaptation on the new platform from the perspective of the users.

As future work, the cognitive stimulation game in mobile platforms should be evaluated by specialists on the EF area. This step should validate if the predominant Executive Functions component on each activity remains the same in the new version of the game. Besides, concerns regarding the game's information clarity, understandability and suitability for the target audience should also be evaluated in the new platform, and added to the development cycle if any correction is necessary. Furthermore, the mobile version of the game will be used in pilot-study program with Elementary School children in school context, to adjust the game balance, as well as to evaluate the possible contributions of the new game and platform in EF stimulation programs.

\section{Acknowledgements}

This study was financed in part by the Coordenação de Aperfeiçoamento de Pessoal de Nível Superior - Brasil (CAPES) - Finance Code 001. Also, we thank the National Council for Scientific and Technological Development - CNPq/Brazil (http://www.cnpq.br) for providing financial support for this study. Finally, we would like to thank Feevale University (http://www.feevale.br) for embracing this research.

\section{Bibliographic References}

AU, J.; SHEEHAN, E.; TSAI, N.; DUNCAN, G.; BUSCHKUEHL, M.; JAEGGI, S. Improving fluid intelligence with training on working memory: A meta-analysis. Psychonomic Bulletin \& Review, v.22, n.2, p.366-377, 2015. Doi:10.3758/s13423-014-0699-x

BABA, Y.; TSCHANG, F. Product development in Japanese TV game software: The case of an innovative game. International Journal of Innovation Management, v.5, n.4, p.487-515, 2001. V. $18 \mathrm{~N}^{\mathrm{o}} 1$, julho, 2020 DOI: RENOTE 
BERNIER, A.; CARLSON, S..; WHIPPLE, N. From external regulation to self-regulation: Early parenting precursors of young children's executive functioning. Child Development, v. 81, n. 1, p. 326-339, 2010.

BLAIR, C.; RAZZA, R. Relating effortful control, executive function, and false belief understanding to emerging math and literacy ability in kindergarten. Child Development, v.78, n.2, p.647-663, 2007.

BUELOW, M.; OKDIE, B.; COOPER, A. The influence of video games on executive functions in college students. Computers in Human Behavior, v.45, p.228-234, 2015.

BULL, R.; ESPY, K. A.; WIEBE, S. A. Short-term memory, working memory, and executive functioning in preschoolers: Longitudinal predictors of mathematical achievement at age 7 years. Developmental Neuropsychology, v.33, n.3, p.205-228, 2008.

BUSCHKUEHL, M.; JAEGGI, S. Improving intelligence: A literature review. Swiss Medical Weekly, v.140, n.19-20, p.266-272, 2010. Doi:10.1.1.613.2047

CONKLIN, H.; LUCIANA, M.; HOOPER, C.; YARGER, R. Working memory performance in typically developing children and adolescents: Behavioral evidence of protracted frontal lobe development. Developmental Neuropsychology, v.31, n.1, p.103-128, 2007.

DIAMOND, A. Executive functions. Annual Review of Psychology, v.64, p.135-168, 2013.

DIAMOND, A.; LEE, K. Interventions shown to aid Executive Function development in children 4 to 12 years old. Science, v.333, n.6045, p.959-964, 2011. DOI: $10.1126 /$ science. 1204529

DIAMOND, A; LING, D. Conclusions about interventions, programs, and approaches for improving executive functions that appear justified and those that, despite much hype, do not.

Developmental Cognitive Neuroscience, v. 18, p.34-48, 2016.

FINCO, M.; REATEGUI, E.; ZARO, M.; SHEEHAN, D.; KATZ, L. Exergaming as an alternative for students unmotivated to participate in regular physical education classes. International Journal of Game-Based Learning (IJGBL), v.5, n.3, p.1-10, 2015.

FRIEDMAN, N.; MIYAKE, A. Unity and diversity of executive functions: individual differences as a window on cognitive structure. Cortex, v.86, p.186-204, 2017.

HUGHES, C.; ENSOR, R. Executive function and theory of mind: Predictive relations from ages 2 to 4. Developmental Psychology, v.43, n.6, p.1447-1459, 2007.

JURADO, M.; ROSSELLI, M. The elusive nature of executive functions: a review of our current understanding. Neuropsychology Review, v.17, n.3, p.213-233, 2007.

KANODE, C.; HADDAD, H. Software engineering challenges in game development. IEEE $6^{\text {th }}$ International Conference on Information Technology: New Generations, p.260-265, 2009.

KOSTER, R. Theory of Fun for Game Design. 2nd Ed. California: O'Reilly Media Inc., 2013. MOSSMANN, J.; REATEGUI, E.; BARBOSA, D.; FONSECA, R.; CARDOSO, C.; \& VALADARES, V. Evaluation of the Usability and Playability of an Exergame for Executive Functions Stimulation and Its Development Process. International Conference on Engineering Psychology and Cognitive Ergonomics (EPCE 2017). Springer, Cham, pp. 164-179, 2017.

MOSSMANN, J. Exergames Como Mediadores Da Estimulação De Componentes Das Funções Executivas Em Crianças Do Ensino Fundamental I. Porto Alegre: PPGIE/UFRGS, 2018. 261p. Tese de Doutorado.

REDICK, T. S.; SHIPSTEAD, Z.; WIEMERS, E.; MELBY-LERVÅG, M.; HULME, C. What's working in working memory training? An educational perspective. Educational Psychology Review, v.27, n.4, p.617-633, 2015. Doi:10.1007/s10648-015-9314-6

THORELL, L. B., LINDQVIST, S., BERGMAN NUTLEY, S., BOHLIN, G., \& KLINGBERG, $\mathrm{T}$. Training and transfer effects of executive functions in preschool children. Developmental Science, v.12, n.1, p.106-113, 2009. DOI: 10.1111/j.1467-7687.2008.00745.x

TOLL, S. W., VAN DER VEN, S. H., KROESBERGEN, E. H., \& VAN LUIT, J. E. Executive functions as predictors of math learning disabilities. Journal of Learning Disabilities, v.44, n.6, p.521-532, 2011. DOI: 10.1177/0022219410387302

WELSH, J. A., NIX, R. L., BLAIR, C., BIERMAN, K. L., \& NELSON, K. The development of cognitive skills and gains in academic school readiness for children from low-income families. Journal of Educational Psychology, v.102, n.1, p.43-53, 2010. DOI: 10.1037/a0016738 